\title{
O NOVO DESENHO INSTITUCIONAL DO MINISTÉRIO PÚBLICO E O PROCESSO DE JUDICIALIZAÇÃO DA POLÍTICA
}

\author{
Ernani Carvalho e Natália Leitão
}

THE NEW PUBLIC ATTORNEY AND PROCESS OF JUDICIALIZATION OF POLITICS

\section{RESUMO}

QUE MECANISMOS EXPLICAM O PROCESSO DE AUTONOMIZAÇÃO do Ministério Público? Este trabalho tem como objetivo PRINCIPAL DISCUTIR O PROCESSO PELO QUAL ESSA INSTITUICCÃO ADQUIRIU, A PARTIR DA CONSTITUINTE DE 1987/88, AUTONOMIA Diante dos Poderes do Estado e como tal autonomia CONTRIBUI PARA O PROCESSO DE JUDICIALIZAÇĀO DA POLÍTICA. COMO A LITERATURA EXPLICA O FATO DE VÁRIAS INSTITUIÇÕES TEREM FEITO LOBBy E APENAS O MinistéRIO Público teVE SUAS ATRIBUIÇÕES AMPLIADAS? PARA ISSO, FOI REALIZADA UMA SISTEMÁTICA REVISÃO TEÓRICA ACERCA DA SUA AUTONOMIZAC̣ĀO. OS RESULTADOS INDICAM QUE O DEBATE SE DIVIDE EM DUAS CORRENTES EXPLICATIVAS. POR UM LADO, DEFENDE-SE QUE A AUTONOMIA DA INSTITUIÇÃO PODE SER EXPLICADA A PARTIR DE DISPOSITIVOS LEGAIS INTERNOS AO PRÓPRIO MINISTÉRIO PúBLICO. POR OUTRO, SUGERE-SE A EXISTÊNCIA DE INTERESSES EXógenos à institucionalidade do Ministério Público no PROCESSO QUE INFLUENCIOU POSITIVAMENTE A AUTONOMIA DESSA INSTITUIC̣ÃO.

\section{PALAVRAS-CHAVE}

CONTROLES DEMOCRÁTICOS; MINISTÉRIO PÚBLICO; JUDICIALIZAÇÃo DA POLITICA.

\begin{abstract}
WHICH MECHANISMS EXPLAIN THE GROWING OF THE PUBLIC ATtORNEY'S AUTONOMY? THIS PAPER DISCUSSES THE PROCESS WHEREBY PUBLIC ATTORNEY ACQUIRED AUTONOMY BEFORE STATE POWERS, SINCE THE DRAWING OF THE NEW BRAZILIAN CONSTITUTION IN 1987/88, AND HOW THIS AUTONOMY CONTRIBUTED TO INCREASE THE JUDICIALIZATION OF POLITICS. HOW DOES THE LITERATURE EXPLAIN THE FACT THAT MANY INSTITUTIONS LOBBIED FOR AUTONOMY AND ONLY PUBLIC ATTORNEY HAD ITS COMPETENCE EXPANDED? A SYSTEMATIC THEORETICAL REVIEW OF THIS PROCESS IS PRESENTED HERE TO TRY TO ANSWER THIS QUESTION. THE RESULTS INDICATE THAT THE DEBATE IS DIVIDED BETWEEN TWO EXPLANATORY CURRENTS. ON THE ONE HAND, THE AUTONOMY OF INSTITUTION COULD BE EXPLAINED BY THE INTERNAL NORMS THAT GOVERN IT. ON THE OTHER HAND, IT'S SUGGESTED THE EXISTENCE OF EXOGENOUS INTERESTS THAT HAD INFLUENCE IN THE CONSTRUCTION OF PUBLIC ATTORNEY'S AUTONOMY.
\end{abstract}

\section{KEYWORDS}

DEMOCRATIC CONTROL; PUBlic ATTORNEY; JUDICIALIZATION OF POLITICS.

\section{INTRODUÇÃO}

O sistema político brasileiro tem passado por inúmeras mudanças nos seus processos de decisão. Inserido nessas alterações, principalmente a partir do processo de redemocratização, iniciado em 1985 e com seu auge na Constituição de 1988, está o sistema de justiça, formado por diversas instituições, dentre elas, o Judiciário, a Defensoria Pública, as Polícias e o Ministério Público. 
Dentre tais instituições, a que mais sofreu modificações significativas pela Constituinte de 1987/88 foi o Ministério Público. Isto porque, anteriormente ligado ao Executivo, a instituição adquiriu autonomia funcional, passando a ser independente de todos os Poderes do Estado e a deter atribuições bastante reforçadas de representante da sociedade. Sem dúvida, essa mudança de status fez com que o Ministério Público fosse capaz de atuar como um relevante ator político (SADEK, 2000; ARANTES, 2002; KERCHE, 2003).

A história do Ministério Público mostra que algumas de suas prerrogativas foram adquiridas antes da Constituição de 1988. Por exemplo, o Código de Processo Civil de 1973 determinou que o Ministério Público deveria atuar em todas as causas que houvesse interesse público o que, segundo Arantes (2002), já demonstra o início do afastamento do Poder Executivo. Mas é somente na década 1980 que a instituição sofre as modificações mais importantes. Destaca-se, neste sentido, a Lei nº 6938/81 de Política Nacional de Meio Ambiente, que incluiu novos instrumentos processuais e deu legitimidade ao Ministério Público para proposição de ação de responsabilidade civil e criminal por danos causados ao meio ambiente.

Todavia, é apenas com a Constituição de 1988 que o Ministério Público passa a se utilizar dos mecanismos adquiridos ao longo da sua história de maneira autônoma o que, decididamente, faz uma grande diferença (KERCHE, 2003). A instituição deixou de atuar como apêndice do poder executivo, fazendo com que suas ações fossem tidas como do próprio governo, e passou a agir como um órgão independente. Além disso, obteve a importante função de fiscalizar o cumprimento das leis e os próprios políticos, passando a fazer parte da sua alçada a função de representante da sociedade. Ou seja, foram garantidos ao Ministério Público papéis importantes dentro do cenário político nacional e tais papéis podem ser exercidos de maneira autônoma.

Dito isso, o objetivo deste trabalho é identificar quais são as variáveis utilizadas pela literatura especializada para explicar de que maneira essa instituição adquiriu autonomia. De que maneira o lobby organizado pela Confederação Nacional do Ministério Público (Conamp) conseguiu que boa parte das suas demandas fosse atendida? De que maneira os congressistas "permitiram" a aprovação de um Ministério Público independente de todos os Poderes de Estado? E ainda, essa alta autonomia da instituição foi acompanhada pelos mecanismos necessários de controle e accountability? Como tal autonomia contribui para o processo de judicialização da política?

Enfatizamos que a literatura sobre este tema no Brasil ainda é escassa. Adotou-se como estratégia metodológica mapear e revisar os trabalhos relevantes e seguir os fundamentos teóricos da literatura internacional de controles democráticos. Além disso, destacamos que a questão que nos orienta é essencialmente política, por isso o foco nos trabalhos na área da ciência política. 
O artigo está dividido em três seções. A primeira delas é uma descrição do desenho institucional adquirido pela instituição em questão, apresentando as correntes teóricas que explicam como foi possível para o Ministério Público obter novas atribuições e garantias, mostrando suas virtudes e limitações. Em seguida são examinados os mecanismos capazes de afetar a autonomia do Ministério Público brasileiro e se é garantida a accountability pertinente em uma democracia. Por fim, a última seção busca fazer uma breve análise de como essa autonomia adquirida afeta o processo de judicialização da política.

\section{i O atual desenho institucional do Ministério Público}

Pode-se afirmar que o atual desenho institucional do Ministério Público começou a ser moldado antes mesmo da Constituição de 1988 (ARANTES, 2002). As mudanças mais significativas no Parquet $^{1}$ se deram a partir da década de 1980. A Lei n 6938/81 de Política Nacional de Meio Ambiente incluiu novos instrumentos processuais e deu legitimidade ao Ministério Público para proposição de ação de responsabilidade civil e criminal por danos causados ao meio ambiente.

Com a primeira Lei Orgânica Nacional do Ministério Público (LC federal nº 40, de 1981), a instituição passou a ter um perfil nacional mais uniforme, com conceituação, princípios, funções, garantias, vedações, instrumentos e organização básica comuns. Destaca-se ainda a Lei $n^{\circ} 7347 / 85$, que regulamentou a ação civil pública, definindo seu objeto, a legitimação para utilizá-la, as atribuições do Ministério Público e criou o inquérito civil.

A Constituição de 1988 garantiu um Ministério Público mais forte. Explicações como a de Arantes $(1999,2002)$ e de Silva (2001) defendem a ideia de que a Carta Magna apenas consolidou o que a instituição já havia conseguido com as leis ordinárias e complementares referidas. Eles analisam a importância dessas mudanças ocorridas a partir de 1980 e consideram que a Constituição apenas fechou um ciclo.

Soa lugar comum a idéia de que a Constituição de 1988 deu ao país um novo Ministério Público. Todavia, [...] essa afirmação não é verdadeira, uma vez que boa parte dos avanços conquistados pela instituição ocorreu no período anterior. Antes mesmo da eleição para o Congresso Constituinte, em 1986, e com menos de um ano de retorno ao governo civil, com José Sarney, os principais elementos desse novo Ministério Público já estavam dados: fiscal da constitucionalidade das leis e atos normativos dos poderes políticos desde o início do regime militar, guardião do interesse público ampliado desde 1973, instituição definida como permanente e essencial à prestação jurisdicional desde 1981 e, finalmente, agente principal da defesa dos interesses difusos e coletivos pela Lei da ação civil pública de 1985 (ARANTES, 2002: 76). 
Entretanto, com nova Constituição, foi concedida ao Parquet autonomia funcional, uma das principais garantias da instituição, que consiste da possibilidade de tomar decisões sem injunções de outros órgãos ou Poderes do Estado. É óbvio que essa garantia faz uma grande diferença no perfil institucional do Ministério Público. Um exemplo que pode ser dado é com relação à ação civil pública, um dos principais instrumentos de atuação da instituição. ${ }^{2}$ Embora esse tipo de ação tenha sido prevista antes de 1988, com o advento da nova Constituição, esse instrumento deixou de ser utilizado por uma organização ligada ao poder Executivo, o que fazia das ações do MP ações do próprio governo. Ou seja, com a Constituição de 1988, além de se utilizarem da ação civil pública para fiscalizar o correto cumprimento da lei, os promotores e procuradores de Justiça passaram a fazer isso de forma independente em relação aos políticos, o que, para Kerche (2003), representa uma grande diferença. Ademais, esse instrumento foi ampliado de forma considerável para todos os interesses difusos e coletivos. Tudo isso garante um alto grau de autonomia ao Ministério Público brasileiro, sendo possível só após a Constituição de 1988.

Além da autonomia funcional, foi garantida também a autonomia administrativa, que consiste da possibilidade de o Ministério Público, apenas subordinado à lei, praticar os atos próprios de gestão administrativa da instituição. Embora não tenha sido assegurada de forma expressa a autonomia financeira, o Ministério Público tem a capacidade de elaborar sua proposta orçamentária, dentro dos limites definidos por lei específica, de gerir e aplicar os recursos destinados à instituição e de administrar o emprego das dotações orçamentárias (MAZZILLI, 2005: 42-43).

O posicionamento constitucional do Ministério Público não o vincula a nenhum dos Poderes do Estado, estando o mesmo inserido em capítulo à parte, "Das funções essenciais à Justiça”. Esse posicionamento, segundo Mazzilli (2005), não faz com que o Parquet possa ser considerado um quarto Poder do Estado, mas sem dúvida, a instituição adquiriu efetivamente algumas garantias de poder.

$\mathrm{O}$ art. 127 da Constituição define o Ministério Público como "instituição permanente, essencial à função jurisdicional do Estado, incumbido-lhe a defesa da ordem jurídica, do regime democrático e dos interesses sociais e individuais indisponíveis”. Ou seja, a instituição não pode ser abolida pelo poder constituinte derivado; embora não oficie em todos os processos judiciais, naqueles em que deve oficiar sua atuação é essencial para a prestação jurisdicional; a instituição deve zelar pelo cumprimento da lei e é sempre encarregada da defesa dos direitos sociais e da defesa dos direitos individuais quando indisponíveis (MAZZILLI, 2005).

Esquematicamente, o Ministério Público abrange o Ministério Público da União - que por sua vez compreende o Ministério Público Federal, o Ministério Público do Trabalho, o Ministério Público Militar e o Ministério Público do Distrito Federal e Territórios - e o Ministério Público dos Estados. Do ponto de vista constitucional, destaca-se a unidade e a indivisibilidade como princípios básicos que orientam 
o funcionamento de tal instituição. O primeiro quer dizer que o Parquet é um só órgão, sob uma só chefia. Mas, por conta dos ramos citados, essa regra é válida para cada Ministério Público (MAZZILLI, 2005). Vale ressaltar que essa chefia é administrativa e não funcional, já que cada membro do Ministério Público goza de independência para exercer suas funções em face dos outros membros, no exercício da atividade-fim ${ }^{3}$. Em outras palavras, existe independência funcional, mas não hierarquia funcional. Isso quer dizer que estamos diante de uma estrutura monocrática, na qual um Procurador-Geral não pode intimar um promotor a agir de um certo modo, assim como não pode trocar um membro do Ministério Público no meio de um caso, por exemplo. Além disso, um integrante da instituição pode ser promovido apenas pelo tempo de serviço fazendo com que aquilo que poderia ser motivação para um "alinhamento" ao chefe da organização seja limitado por restrições às preferências do Procurador-Geral (KERCHE, 2003).

Essas duas características, a falta de uma estrutura hierárquica e independência funcional dos promotores, criam uma barreira à formação de políticas institucionais uniformes. Por um lado, existe alguma vantagem, já que os promotores e procuradores têm mais liberdade para se adaptar às realidades específicas, "podendo tomar medidas inovadoras que seriam dificultadas se fosse necessário esperar uma ordem da cúpula do Ministério Público" (KERCHE, 2003: 119). Por outro lado, esse desenho diminui a garantia de que todos os cidadãos devem ter seus direitos defendidos de forma isônoma.

Como analisado, é bem verdade que o Ministério Público passou por mudanças significativas desde o início da década de 1980. Todavia, várias garantias adquiridas pela instituição e pelos seus membros só foram possíveis com a Carta de 1988. Dito isto, resta saber quais são as perspectivas teóricas existentes explicar um desenho institucional tão peculiar quanto o do Ministério Público brasileiro.

\section{I As EXPLICAÇões TeÓRICAS SOBRE O NOVO DESENHO INSTITUCIONAL do Ministério Público}

O debate teórico acerca do Ministério Público no Brasil ainda é incipiente (MCALLISTER, 2008). Inicialmente, a preocupação da literatura é explicar os fatores que motivaram a autonomização do Ministério Público. O debate se divide basicamente em duas correntes explicativas: (1) há argumentos endógenos, ou seja, o que possibilitou essa autonomização foram dispositivos legais construídos de dentro para fora do Ministério Público; (2) há os argumentos exógenos, que apontam para a existência de interesses fora da institucionalidade do Ministério Público no processo que acarretou o aumento da autonomia de tal instituição.

Para a primeira explicação, os integrantes do MP, detentores de um "voluntarismo" político, perseguiram a reconstrução da instituição. Segundo Arantes, "a observação da atuação do Ministério Público revela que setores dentro da instituição têm se dedicado 
enfaticamente à sua transformação em instrumento de luta pela construção de cidadania” (ARANTES, 1999: 84).

A hipótese assumida por Arantes (2002) é de que a reconstrução institucional do Ministério Público foi construída endogenamente, ou seja, as mudanças ocorridas na instituição foram motivadas intencionalmente pelos seus próprios integrantes. E é exatamente para destacar essa dimensão endógena que o autor se utiliza da noção de voluntarismo político, mostrando que o êxito do Ministério Público no que tange a conquista de autonomia frente aos outros Poderes do Estado é resultado da ação consciente e deliberada dos próprios integrantes da instituição:

Os resultados da nossa pesquisa empírica [...] demonstram que esse processo teve fortes traços endógenos: os próprios integrantes do Ministério Público, imbuídos da convicção de que devem se tornar defensores da sociedade, desenvolveram ações dentro e fora de seu círculo normal de atribuições, com vistas a transpor fronteiras do sistema de justiça stricto sensu e invadir o mundo da política. A análise desse fenômeno de origem endógena nos levou a construir o conceito de voluntarismo político, pelo qual pretendemos explicar o modo como o Ministério Público se transformou em um novo ator político (ARANTES, 2002: 15).

Em outras palavras:

Em síntese, o que se pretende salientar é que o Ministério Público de hoje é resultado, em grande medida, do que desejaram e fizeram seus próprios integrantes, para além ou aquém das tendências do meio ambiente institucional e a despeito de visões internas divergentes terem ficado pelo caminho. Embora se reconheça que essas outras duas dimensões sejam importantes, orientar-se por elas seria perder de vista o que temos de mais precioso nessa história: o voluntarismo político de promotores e procuradores e seus valores ideológicos peculiares. Focalizar o curso de ação vitorioso desses (re)construtores institucionais parece bem mais interessante do que tentar mostrar a influência do meio ambiente, ou ainda do que contar a história dos que foram derrotados no embate interno ou que simplesmente se deram por satisfeitos com as funções tradicionais da instituição (ARANTES, 2002: 22-23).

Casagrande (2008) apresenta visão similar ao afirmar que:

Para a definição deste novo perfil institucional do Ministério Público foi decisiva a atuação eficaz e articulada dos seus membros no período da 
reconstitucionalização do país, numa clara mostra do ativismo político que viria marcar a instituição nas décadas seguintes. As associações estaduais de membros do Ministério Público, congregadas na CONAMP - Confederação Nacional das Asssociações do Ministério Público - promoveram uma grande mobilização da categoria a respeito de sua futura conformação constitucional e na defesa de suas prerrogativas (CASAGRANDE, 2008: 104).

Defendendo também esta visão, Silva (2001) ressalta a intensa mobilização dos membros do Ministério Público, mostrando uma grande capacidade de articulação e defesa de seus interesses coorporativos e institucionais. Casagrande (2008) ainda destaca outros projetos populares que queriam reformas democratizantes do sistema de justiça e instituições capazes de dar eficácia aos direitos constitucionais e de mediar conflitos sociais.

Soma-se a esse voluntarismo o fato de que os membros do Ministério Público alegavam uma hipossuficiência da sociedade brasileira, ou seja, ela seria pouco organizada e incapaz de defender seus direitos e interesses. Neste sentido, o Ministério Público surge como a instituição responsável por defender os interesses da sociedade:

O argumento é que temos uma sociedade civil fraca, desorganizada e incapaz de defender seus interesses fundamentais. Uma sociedade "hipossuficiente" no jargão jurídico. Além disso, frequentemente é o próprio poder público quem mais desrespeita esses direitos fundamentais. Dessa equação resulta a proposta, de natureza instrumental, de que "alguém” deve interferir na relação Estado/sociedade em defesa dessa última (ARANTES, 1999: 96).

Vale ressaltar que os atores não agem em um vácuo institucional. Arantes (2002) destaca que a interferência ambiental e a inter-relação entre os agentes envolvidos são importantes para o quadro explicativo. O foco nas origens endógenas da reconstrução institucional é mais uma opção metodológica do que do que uma negação da importância dessas dimensões. Ele admite que grande parte das mudanças obtidas pelo Ministério Público foi fruto de alterações legislativas e constitucionais, destacando, assim, o papel dos poderes executivo e legislativo. Todavia, ele defende que mesmo tendo se efetivado na esfera política, tais mudanças nasceram de sugestões e pressões da própria instituição.

De fato, a expansão do direito e a hipossuficiência da sociedade brasileira são fenômenos inegáveis. No entanto, os defensores dessa corrente não deixam tão claro como esses dois fenômenos se articularam de modo a criar condições para o fortalecimento e a autonomização do Ministério Público. A explicação parte do pressuposto de que atores políticos agiram no sentido de fortalecer o Ministério Público, mas não explica o que os levou a agir dessa forma. Também não fica claro quão hipossuficiente 
é a sociedade brasileira, seja em termos comparativos, seja em perspectiva histórica. Ademais, embora o voluntarismo do Ministério Público seja uma fonte de legitimidade (o que fortalece a instituição), existem outras instituições que também têm esse caráter (ONG's, associações, sindicatos) e não atingiram o patamar do Ministério Público.

Por fim, Arantes (2002) adota uma perspectiva utilitária e maximizadora no sentido de que os membros do Ministério Público tinham objetivos a serem atingidos e para isso agiram racionalmente, escolhendo meios adequados para o alcance dos seus fins. No entanto, na coletividade, o caminho da determinação da preferência para a consecução ótima da mesma, na maior parte das vezes, não é perfeito. A interação de agentes racionais com objetivos comuns nem sempre resulta em um resultado coletivo eficiente 4 (OLSON, 1999). Ou seja, o resultado pode ser sub-ótimo para a coletividade. A possibilidade de que o resultado final da Constituição tenha sido sub-ótimo para o membros do Ministério Público não é nem ao menos considerada na explicação de Arantes (2002). Para ele, a história do Ministério Público brasileiro é de sucesso, não tendo a instituição sofrido derrotas significativas nos últimos vinte anos.

Partindo da crítica à ideia de que os membros do Ministério Público agiriam como atores essencialmente jurídicos - como deixa transparecer a primeira corrente explicativa -, a segunda vertente constrói o seu argumento. Para Kerche (2003), ao estudar os promotores e procuradores de justiça, deve-se incluí-los na premissa "negativa” da natureza humana. Para ele, "os homens não são anjos e ao serem admitidos em um concurso público, como acontece para selecionar os promotores, não são transformados em anjos" (KERCHE, 2003: 7).

É bem verdade que os promotores e procuradores souberam se organizar de forma eficiente. Todavia, surge a questão: se várias instituições fizeram lobby, por que justamente o Ministério Público que conseguiu mais ampliar suas atribuições? Tentando responder essa questão, Kerche $(1999 ; 2003)$ aponta alguns fatores que influenciaram a atual estrutura da instituição. Primeiramente, ele aponta o lobby da Conamp. Como demonstrado, esse fator seria uma condição necessária, mas não suficiente, visto que outros grupos também fizeram lobby e não conseguiram adquirir os privilégios do Ministério Público. Sendo assim, Kerche (1999; 2003) formula a hipótese de aprovação do atual modelo de Ministério Público baseado em dois aspectos. Por um lado, a Conamp mostrou uma organização bastante eficiente, "oferecendo aos constituintes uma proposta em forma de texto constitucional [...] e desenvolveu um trabalho de acompanhamento junto às discussões constituintes (lobby) que se mostrou eficaz" (KERCHE, 1999: 67).

Por outro lado, há o aspecto da própria conjuntura política da época. Com o fim do período autoritário, o sentimento de democratização e de fortalecimento das instituições responsáveis pela transparência do Estado aumenta. Assim, "houve relativa 
facilidade para esse lobby operar 'vendendo' aos constituintes a ideia da importância da criação de um agente não-político partidário - responsável pela defesa dos interesses da sociedade" (KERCHE, 1999: 67).

O processo de confecção da Constituição de 1988 é fundamental na explicação de Kerche $(1999,2003)$. A Assembleia Nacional Constituinte é, certamente, um cenário privilegiado de observação e avaliação do novo perfil institucional do Ministério Público. As modificações ocorridas no decorrer da assembleia, notadamente a entrada do "centrão" 5 no jogo político e a mudança do regimento interno, foram decisivas para o desenho institucional final do Parquet. Na verdade, o surgimento do "centrão" parece ter mudado, em certa medida, o perfil do Ministério Público reivindicado pelos membros da instituição e, sendo assim, a história dela não é apenas de sucesso, como quer Arantes (2002).

Ao considerar o contexto político e institucional da Constituinte, baseado no institucionalismo histórico, Kerche (2003) resolve o problema do vácuo institucional encontrado em Arantes (2002). No entanto, nesta versão do novo-institucionalismo é dada uma grande importância às relações assimétricas de poder, à forma como as instituições distribuem poder de forma desigual (HALL; TAYLOR, 2003). Todavia, Kerche (2003) não considera esse aspecto de maneira satisfatória. Embora descreva o ambiente institucional com detalhes, mostrando como a entrada no "centrão" modificou o desenho institucional do Ministério Público, não fica claro como se deu a correlação de forças e como o equilíbrio foi conseguido, considerando que se vivia um momento de bastante incerteza (SALAZAR, 2007).

A tabela abaixo sintetiza essas explicações.

\section{TABEla i - Sumário analítico da literatura} CONSTITUIICÃO TENHA SIDO SUB-ÓTIMO PARA OS MEMBROS DO MP NÃO É CONSIDERADA.

KERCHE (2003) PROCESSO EXÓGENO ÊNFASE INSTITUCIONAL

EXPLICAC̣ÃO O LOBBY DA CONAMP FOI EFICIENTE, OFERECEU AOS CONSTITUINTES UMA PROPOSTA EM FORMA DE TEXTO CONSTITUCIONAL E DESENVOLVEU UM TRABALHO DE ACOMPANHAMENTO JUNTO ÀS DISCUSSÕES CONSTITUINTES. COM O FIM DO PERÍODO AUTORITÁRIO, O SENTIMENTO DE DEMOCRATIZACÃO E DE FORTALECIMENTO DAS INSTITUIÇÕES RESPONSÁVEIS PELA TRANSPARÊNCIA DO ESTADO AUMENTA, HAVENDO RELATIVA FACILIDADE PARA A CONAMP OPERAR, 'VENDENDO' AOS CONSTITUINTES A IDEIA DA IMPORTÂNCIA DA CRIAÇÃO DE UM AGENTE NÃO-POLÍTICO-PARTIDÁRIO RESPONSÁVEL PELA DEFESA DOS INTERESSES DA SOCIEDADE.

LIMITAC̣ÕES NĀO CONSIDERA DE MANEIRA SATISFATÓRIA AS RELAÇÕES ASSIMÉTRICAS DE PODER. EMBORA DESCREVA O AMBIENTE INSTITUCIONAL COM DETALHES, MOSTRANDO COMO AS MUDANÇAS OCORRIDAS NO DECORRER DA CONSTITUINTE modificaram o desenho institucional do Ministério Público, não fiCA CLARO COMO SE dEU A CORRELAÇÃo dE FORÇAS E COMO O EQUILÍBRIO FOI CONSEGUIDO. 
É plausível que um trabalho acadêmico só conte uma parte da história e não explique totalmente um fenômeno já que escolhas teóricas e metodológicas devem ser feitas. O "julgamento" não deve ser realizado com base em quem explica mais, mas sim em como se construiu as categorias analíticas e se tal construção foi feita de maneira satisfatória. Como analisado, ambas as correntes oferecem um modelo explicativo de certa forma incompleto. Considero que uma simples síntese entre elas não seja possível, todavia acredito também que admitir que as explicações utilizam variáveis diferentes não é dizer que as explicações são incompatíveis. Analisar o fenômeno com base simplesmente nas preferências dos membros do Ministério Público, como faz Arantes (2002), é insuficiente. É importante analisar o ambiente político e institucional no qual os atores agem. Kerche (2003) tenta fazer essa análise, mas como demonstrado, a faz de maneira metodologicamente incompleta.

Assim sendo, o debate em ciência política sobre o Ministério Público ainda se mostra bastante incipiente, havendo espaço para outras explicações, que procurem considerar as variáveis explicativas já utilizadas, mas que busquem também novas variáveis e que construa suas categorias de análise de forma mais robusta.

\section{Mecanismos de CONTRole e accountability}

Como analisado, a Constituição de 1988 assegurou ao Ministério Público brasileiro um alto grau de autonomia assim como instrumentos institucionais necessários para que tal autonomia fosse garantida. Pode-se dizer que os políticos brasileiros concederem autonomia funcional aos seus Ministérios Públicos e delegaram aos promotores e procuradores, além do papel tradicional de levar casos criminais aos tribunais, a função de exigir o cumprimento da lei e fiscalizar aqueles que ocupam cargos públicos.

Segundo Przeworski (1998), a relação de delegação entre políticos e burocratas leva a problemas básicos do relacionamento principal-agent. ${ }^{6}$

Como é impossível formular leis que especifiquem todas as ações dos agents sob todas as contingências, as agências executivas e administrativas conservam um espaço considerável de autonomia para decidir. Entretanto, os objetivos dos burocratas não têm necessariamente de ser idênticos aos objetivos dos cidadãos ou dos políticos eleitos que os representam. [...] Eles [os agents] dispõem de informação especial quanto aos benefícios e custos de suas ações, e podem ser inferidos dos resultados ou monitorados como itens de custo. [...] A rigor, dado o inevitável grau de autonomia de que gozam os burocratas, a questão é como evitar que se estabeleça um regime de 'política sem lei' (PRZEWORSKI, 1998: 52-53). 
Ou seja, o principal detém o poder, mas é limitado em tempo, talento e energia. Então ele pode delegar tarefas ao agent, mas deve fazê-lo junto com o poder necessário para realizá-las. O agent detém expertise e pode agir de acordo, ou não, com os interesses do principal (BENDOR et al., 2001). Com isso, pode haver uma assimetria de informação entre o agent e o principal, o que faz com que surja espaço para o oportunismo do agent na execução de suas obrigações (MELO, 1996).

Nesse sentido, embora a delegação possa trazer benefícios ao principal, advindos da expertise e habilidade dos agents, ela pode trazer riscos, isto porque a delegação envolve transferência de poder. Há ainda o risco dos agents abusarem do poder recebido, fazendo com que o principal perca controle do que é feito, gerando uma abdicação (LUPIA, 2001), além da já observada questão da assimetria de informação.

Resta saber se existem mecanismos capazes de afetar, de alguma forma, a autonomia do Ministério Público brasileiro e de reduzir os custos inerentes à relação principal-agent. Essa questão é importante porque, segundo Kerche (2003), "a necessidade de controle para a teoria democrática não se restringe somente aos políticos eleitos, mas deve estender-se a todos os atores estatais que detêm algum grau de discricionariedade" (KERCHE, 2003: 57), como é o caso do Ministério Público. Ao se moldar uma instituição deve sempre se levar em conta o princípio madisoniano de que os homens não são anjos e não será um concurso público que irá transformá-los em anjos. Ou seja, alto grau de discricionariedade combina com mecanismos de controle e accountability, mesmo com relação a agentes não-eleitos. Segundo Kerche (1999; 2003), tais mecanismos existem, mas são insuficientes, não garantindo uma prestação de contas e muito menos mecanismos que recompensem ou punam ações dos procuradores e promotores.

Existem, primeiramente, dois critérios óbvios de avaliação. O primeiro é se há interferências no cotidiano da organização, como a existência de comissões parlamentares responsáveis por fiscalizar os promotores e procuradores, exigência de relatórios de atividades, se são aplicadas sanções aos membros do Ministério Público pelos políticos, etc. O segundo é que, em última instância, os políticos têm o poder de emendar a Constituição e alterar o desenho institucional do Ministério Público, modificando suas garantias e prerrogativas.

Por ambos os critérios há um déficit de accountability. O primeiro é deficiente porque não há comissões que exijam prestação de contas, não ocorrem sanções diretas e nem sequer existem mecanismos institucionais capazes de aplicá-las. Além disso, esse tipo de controle de “patrulha de polícia” não é tão eficiente, já que:

[...] não é porque os políticos não punem constantemente os integrantes do Ministério Público e não fiscalizam diretamente a organização que isto significa, obrigatoriamente, que os promotores não levam em conta o desejo dos políticos e que os políticos não possam reverter o tipo de atuação da 
organização, pelo menos, a médio prazo. Essa falta de punição pode significar que os promotores e procuradores de justiça estão se antecipando aos desejos dos políticos para evitar possíveis punições (Kerche, 2003: 61, grifos nossos).

O segundo é bastante rígido visto que uma instituição que possui previsão constitucional é bem mais protegida de ingerências externas do que uma prevista por lei ordinária. Ou seja, o custo para punir o Ministério Público através de emenda constitucional é muito alto.

Sendo assim, Kerche (2003) propõe outros critérios, menos óbvios, para saber se existem mecanismos capazes de influenciar a atuação dos integrantes do Ministério Público e de reduzir os problemas ligados à relação principal-agent.

O primeiro deles é a criação de múltiplos agents, ou seja, delegar tarefas semelhantes a diferentes atores estatais. Isto é importante porque estabelece competição entre as instituições e "a concorrência facilita a aferição do desempenho e, combinada a incentivos adequados, melhora o desempenho" (PRZEWORSKI, 1998: 56-57). Além disso, as decisões devem ser tomadas com um número maior de informações: com um número maior de agents provavelmente mais informações serão coletadas (PRZEWORSKI, 1998: 56). Sendo assim, os políticos poderiam punir uma instituição que não esteja atuando corretamente e premiar aquela que desempenha melhor o seu papel. No caso do Ministério Público brasileiro, embora divida a titularidade da ação civil pública com outras instituições, o inquérito civil (instrumento complementar a ação civil pública) é monopólio do Parquet o que torna a competição desigual.

No entanto, uma forma eficaz de punir ou premiar uma instituição diz respeito ao controle orçamentário. Existem restrições ao uso desse dispositivo, já que os promotores e procuradores não podem ter seus vencimentos diminuídos (KERCHE, 2003). Sendo assim, segundo Kerche (2003), este tipo de controle seria insuficiente para garantir accountability. Ainda que, de acordo com essa perspectiva, o controle orçamentário possa afetar apenas a efetividade da instituição, não os seus membros, nada garante que o alvo não seja justamente tal efetividade. Segundo Mazzilli (2005), “a simples ampliação de quadros de seus membros, sem conceder-lhes, porém, a infra-estrutura adequada, levará a médio e a longo prazos a deformações muito graves” (MAZZILLI, 2005: 28). Ou seja, conter o crescimento da corporação e criar obstáculos a sua atuação por questões orçamentárias pode ser uma forma eficaz de controlar o Ministério Público.

Outro critério apontado pela literatura é a fiscalização institucional, que "requer que quando se delegue autoridade a um agent, haja pelo menos outro agent com autoridade para vetar ou bloquear a ação daquele" (KIEWIET; MCCUBBINS apud PRZEWORSKI, 1998: 56). Kerche (2003) inclui o Poder Judiciário como uma instituição capaz de exercer certo grau de controle sobre o Ministério Público, afinal, os integrantes do MP propõem a ação, mas quem julga é o Judiciário. Todavia esse 
controle é frágil já que existem mecanismos que permitem a atuação da instituição sem a influência do Judiciário, como os Termos de Ajustamento de Conduta. Além disso, a resposta do Judiciário é por vezes lenta e os procuradores e promotores podem se posicionar publicamente:

Imaginemos, por exemplo, a situação de um prefeito processado pelo Ministério Público estadual. A atuação do promotor responsável pelo caso pode não se restringir ao processo junto ao poder Judiciário. Eventualmente esse promotor possui liberdade institucional para acusar o prefeito publicamente através da imprensa. Ora, para um político pode ser devastador. A questão é que a ação, neste exemplo, ainda não foi julgada e o prefeito é transformado em culpado perante a opinião pública por um agente do Estado (KERCHE, 1999: 66).

Um terceiro critério para analisar se há controle por parte dos políticos sobre o Ministério Público é a indicação do chefe da organização, assim como sua exoneração e a possibilidade de recondução ao cargo. No caso do Ministério Público da União, o Procurador-Geral da República é nomeado pelo presidente, entre os membros de carreira, após ter o nome aprovado pela maioria do Senado. Numa análise preliminar, poderia se chegar à conclusão de que, desta forma, o cargo é de confiança já que o principal escolheria um nome afinado com seus interesses e o Procurador-Geral, agent, iria criar uma política institucional de acordo com os desejos do principal. Sendo que o Procurador-Geral tem mandato fixo, o que já enfraquece o mecanismo de controle, uma vez que ele não pode ser destituído por questões políticas, ou seja, não se trata de um cargo de confiança do presidente. Além disso, para ser destituído é necessária a iniciativa do presidente que deve ser autorizada pela maioria absoluta do Senado. Decorrente disto, observa-se que o Ministério Público da União tem, na verdade, dois principals (o presidente e o Senado), o que dificulta a responsividade ${ }^{7}$ do agent, pois os principals podem não conseguir expressar uma única política. Isto acontecendo, que interesse o agent deve levar em consideração para a sua ação em caso de divergência entre os seus principals?

A possibilidade de recondução ao cargo também é importante, já que é um incentivo para que o agent leve em conta os interesses do principal. Pela regra, o presidente e o Senado podem reconduzir o procurador-geral quantas vezes acharem oportuno. O problema dos múltiplos principals se repete neste caso: com o interesse de ser reconduzido, o procurador-geral não sabe a que desejos deve atender, se os do presidente ou os do senado.

O caso dos ministérios públicos estaduais é um pouco diferente. Os procuradoresgerais de justiça são indicados pelo governador do Estado a partir de uma lista tríplice formada pelos membros do Ministério Público. O mandato do procurador-geral de 
Justiça também é fixo e a destituição é realizada mediante decisão da maioria absoluta do Poder Legislativo estadual, sem ser necessária a interferência do governador. Neste sentido, há também o problema dos múltiplos principals: os colegas de instituição, que votam selecionando os três nomes, o governador, que faz a escolha entre os três, e o Legislativo estadual, que tem o poder de exoneração, ou seja, a responsividade do agent é ainda mais difícil. Uma diferença importante é que o Procurador-Geral de Justiça só pode ser reconduzido ao cargo uma vez, o que poderia torná-lo incontrolável em seu segundo mandato, já que ele não tem incentivo para observar e levar em consideração os desejos do principal. (KERCHE, 2003). Por outro lado, caso houvesse apenas um principal, como por exemplo o governador, haveria um sério risco da instituição se tornar uma extensão do governo.

Por fim, há o "alarme de incêndio", mecanismo de accountability da burocracia para os cidadãos (PRZEWORSKI, 1998). Este mecanismo é importante porque os agents podem esconder informações dos principals. Sendo assim:

[...] precisamente pelo fato de a burocracia estatal prestar serviços aos cidadãos, são os cidadãos quem têm a melhor informação sobre seu desempenho. Além disso, se os políticos se preocupam com o bem-estar dos cidadãos, então os interesses dos cidadãos coincidem com os interesses dos políticos, que são os principals, e não com os interesses dos burocratas, que são os agents (PRZEWORSKI, 1998: 58).

Neste sentido, o mecanismo, no caso do Ministério Público brasileiro, se torna débil porque só é eficiente se houver atuação de grupos de pressão bem organizados, caso contrário estes não serão “ouvidos" pelos políticos. A própria função institucional do Ministério Público limita o mecanismo já que nem sempre suas ações são voltadas para grupos organizados, se referindo muitas vezes a indivíduos ou grupos dispersos. Ademais, como salienta Przeworski (1998), esse tipo de supervisão exige mecanismos institucionais que facilitem o monitoramento da burocracia por parte dos cidadãos, a transmissão de informações e a punição de violações. Como observado, esses mecanismos não existem no Ministério Público brasileiro. Neste caso, o problema é duplo: além de os cidadãos, por vezes, não conseguirem fazer com que o alarme dispare, os políticos não detêm mecanismos institucionais capazes de modificar a atuação de seus agents, mesmo que o alarme dispare.

A partir de então, Kerche (2003) afirma que dizer que houve uma abdicação ${ }^{8}$ dos políticos no que tange ao Ministério Público é um exagero. Por outro lado, afirmar que os políticos delegaram novas tarefas aos promotores e procuradores de justiça é simplista, já que houve a criação de uma série de instrumentos que dificultam a intervenção do Executivo ou do Legislativo na instituição. "Entre a abdicação e a delegação, surge um fenômeno intermediário: alto grau de autonomia, embora com alguns 
poucos instrumentos de controle e accountability" (KERCHE, 2002: 64). Seria o que Kerche chama de quasi-abdicação. Embora não tenha havido uma abdicação completa, já que os políticos ainda podem emendar a Constituição, modificar a legislação infraconstitucional ou influenciar o orçamento proposto pelo Ministério Público, houve um processo que garantiu espaço para autonomia e tarefas pouco comuns a agências estatais não eleitas além de não deixarem margens para punição.

Esse fenômeno em si não representa um problema. A questão é que "[...] quando se limita o grau de discricionariedade, as chances de arbitrariedades também diminuem, tornando-se mais razoável, em uma democracia, a existência de agências com altas doses de autonomia" (KERCHE, 2003: 76). A peculiaridade do Ministério Público brasileiro é que foi feito exatamente o contrário: paralelamente a sua autonomização, os constituintes garantiram um alto grau de discricionariedade a esses agentes não-eleitos do Estado, pouco comum à democracia. Como afirmado anteriormente, a linha de argumentação de Kerche (2003) é que a necessidade de controle não deve se restringir apenas aos políticos eleitos, mas também a todos os atores estatais que detêm algum grau de discricionariedade.

Com relação a sua função "clássica” de propor a ação penal pública, o grau de discricionariedade é relativamente baixo, já que as funções são dividas entre a Polícia e o Judiciário (a polícia investiga, o promotor acusa e o juiz determina a pena), tendo esses últimos algum controle sobre o Ministério Público. Todavia, ao observamos as funções que vão além da ação penal (fiscalização de políticos e burocratas e do cumprimento da lei), ao Ministério Público é garantida uma alta dose de discricionariedade. Esse é o real problema de uma instituição com esse perfil, já que discricionariedade deve ser um elemento da política, não da burocracia:

Trocar a discricionariedade de um agente eleito por um não-eleito protegido por independência não é trocar seis por meia dúzia: é trocar a capacidade de punição dos eleitores daqueles que desrespeitam os desejos dos cidadãos, por aqueles que dificilmente podem ser punidos. É trocar aqueles que têm um incentivo direto para levar em conta o desejo dos eleitores por aqueles que não têm esse incentivo (KERCHE, 2003: 93).

Um último ponto deve ser ressaltado. Embora existam poucos mecanismos de accountability (e os que existem são deficientes) para que os políticos exerçam controle sobre o Ministério Público, essa instituição se apresenta como uma agência de accountability horizontal, ${ }^{9}$ exercendo a função de fiscalizar outros atores estatais. O’Donnell (1998) a define da seguinte forma:

Accountability horizontal: a existência de agências estatais que têm o direito e o poder legal e que estão de fato dispostas e capacitadas para realizar ações, 
que vão desde a supervisão de rotina a sanções legais ou até o impeachment contra ações e emissões de outros agentes ou agências do Estado que possam ser classificadas como delituosas (O’DONNELL, 1998: 40).

Duas implicações decorrem dessa afirmação. A primeira é que para as democracia modernas os mecanismos clássicos de checks and balances apenas entre os três Poderes do Estado não são suficientes. Segundo O’Donnell (1998), esses mecanismos incluem as instituições clássicas do Executivo, Legislativo e Judiciário, mas nas poliarquias contemporâneas também deve se estender por várias agências estatais de supervisão, como os ombudsman e as instâncias responsáveis pela fiscalização das prestações de contas. No caso do Brasil, o Ministério Público deve ser incluído como uma dessas instituições.

Segundo, mostra a insuficiência da accountability vertical, com relação àqueles que elegeram o ocupante de um cargo público. De acordo com O’Donnell (1991), para uma democracia ser consolidada é necessário que haja a accountability do nível horizontal. Acontece que há uma grande diferença entre agências que levantam informações para os eleitores julgarem e aquelas que podem levar os políticos ao banco dos réus, como é o caso do Ministério Público (KERCHE, 2003).

Sendo assim, observa-se uma instituição com alto grau de autonomia e discricionariedade juntamente com insuficientes mecanismos de accountability para que os políticos exerçam algum tipo de controle sobre o Ministério Público e seus membros, o que é pouco comum numa democracia. Adiciona-se a isso o fato dessa mesma instituição exercer parte do controle sobre os políticos, surgindo como uma agência de accountability. Ou seja, embora seja uma instituição que controle outras, o controle sobre ela mesma é tênue. A questão que surge é um velho dilema: quem controla os controladores?

\section{Ministério Público E Judicialização da POlíticA}

Com o processo de transição política, a presença de instituições judiciais, assim como seus procedimentos e agentes, tem se ampliado na democracia brasileira. Diversos estudos surgiram no intuito de analisar as relações das instituições judiciais com as instituições políticas e utilizam um termo que serve para orientar o debate: judicialização da política. ${ }^{10}$

Embora seja um conceito amplamente utilizado, não há um consenso sobre a sua definição. Oliveira e Carvalho (2006) dividem a literatura que trata do tema em duas grandes vertentes:

1) sociológica: que busca explicar o processo por uma conjunção de fatores macro sociológicos e políticos, explorando, por exemplo, se a expansão do Judiciário é benéfica ou maléfica para a democracia (Cappelletti e Garapon); 
2) institucional: quando se focaliza os aspectos e arranjos institucionais referentes ao Judiciário e sua relação com o meio político, como por exemplo, a descrição das condições políticas existentes em cada país no momento em que se verifica indícios de judicialização (Castro, Vianna et al, Tate e Vallinder) (p. 125,126).

Para Castro (1997), baseado na leitura de Tate e Vallinder (1995), a judicialização da política é um fenômeno observado em diversas sociedades contemporâneas e apresenta dois componentes:

(1) um novo 'ativismo judicial', isto é, uma nova disposição de tribunais judiciais no sentido de expandir o escopo das questões sobre as quais eles devem formar juízos jurisprudenciais (muitas dessas questões ficavam reservadas ao tratamento dado pelo Legislativo ou pelo Executivo); e (2) o interesse de políticos e autoridades administrativas em adotar (a) procedimentos semelhantes aos processos judiciais e (b) parâmetros jurisprudenciais em suas deliberações (muitas vezes, o judiciário é politicamente provocado a fornecer esses parâmetros) (CASTRO, 1997, p.148).

Neste segundo componente, poderíamos chegar à conclusão de que a judicialização da política acaba por "despolitizar" o processo político no sentido de que deixariam de ser adotados métodos políticos tradicionais de resolução de conflitos para serem adotados métodos jurídicos. Por isso que vários políticos e estudiosos são reticentes com esse processo, já que se substitui o julgamento político de representantes normalmente eleitos por um julgamento de agentes não-eleitos. Trocam-se aqueles que têm um incentivo direto para levar em conta o desejo dos eleitores por aqueles que não têm esse incentivo e, assim, perde-se a capacidade de punição dos eleitores daqueles que desrespeitam os desejos dos cidadãos.

Já Arantes (1999) admite a importância da dimensão do ativismo, já que ele expressaria o lado politizado da justiça, contrapartida da judicialização da política. Todavia, ele afirma que a judicialização só pode ser compreendida a partir de uma descrição do quadro institucional e das regras que permitem ou impedem ações tipicamente políticas por parte dos tribunais. Ou seja, é necessário explicitar quais as formas que o Judiciário tem de atuar que possa influenciar o processo político.

Vianna (2002) trata o fenômeno da judicialização "em termos de procedimentalização do direito e da ampliação dos instrumentos judiciais como mais uma arena pública a propiciar a formação da opinião e o acesso do cidadão à agenda das instituições políticas" (MACIEL; KOERNER, 2002: 117). 
O quadro abaixo resume os principais argumentos sobre a judicialização da política.

\section{Quadro i : Quadro analítico da judicialização da política}

\begin{tabular}{|c|c|c|c|}
\hline AUTORES & $\begin{array}{l}\text { AUMENTO DA INFLUÊNCIA } \\
\text { DO PODER JUDICIÁRIO }\end{array}$ & $\begin{array}{l}\text { CRIATIVIDADE JURISDICIONAL } \\
\text { /ATIVISMO JUDICIAL }\end{array}$ & JUDICIALIZAC̣ÃO DA POLÍTICA \\
\hline $\begin{array}{r}\text { MAURO } \\
\text { CAPPELLETTI } \\
\text { (1993] }\end{array}$ & $\begin{array}{l}\text { CONSEQUÊNCIA DA EXPANSÃO DO } \\
\text { ESTADO EM TODOS OS SEUS RAMOS } \\
\text { COM O ADVENTO DO WELFARE STATE. }\end{array}$ & $\begin{array}{l}\text { INERENTE À ATIVIDADE DO JUIZ E NÃO } \\
\text { PREJUDICIAL À ORDEM DEMOCRÁTICA. } \\
\text { CONSIDERA A CRIATIVIDADE CRUCIAL } \\
\text { PARA ENTENDER A INTERVENÇÃO DO } \\
\text { JUDICIÁRIO NA POLÍTICA. }\end{array}$ & $\begin{array}{l}\text { A JUDICIALIZACCÃO ESTÁ LIGADA AO } \\
\text { ATIVISMO JUDICIAL. ELE CONSIDERA } \\
\text { UMA COISA INDISSOCIÁVEL DA OUTRA. }\end{array}$ \\
\hline $\begin{array}{r}\text { ANTOINE } \\
\text { GARAPON } \\
\text { (1999] }\end{array}$ & $\begin{array}{l}\text { CONSEQUÊNCIA DO } \\
\text { ENFRAQUECIMENTO DO ESTADO PELO } \\
\text { MERCADO, DO DESMORONAMENTO } \\
\text { SIMBÓLICO DO MUNDO POLÍTICO } \\
\text { E FRACASSO DAS INSTÂNCIAS DE } \\
\text { RESOLUÇÃO DE CONFLITOS } \\
\text { TRADICIONAIS (FAMÍLIA, IGREJA ETC.) } \\
\text { E DO FIM DO MUNDO SOCIALISTA E } \\
\text { DA BIPOLARIZAÇÃO DO MUNDO. }\end{array}$ & $\begin{array}{l}\text { RECONHECE OS BENEFÍCIOS DA } \\
\text { INTERVENÇÃO JUDICIAL E ALERTA } \\
\text { PARA A POSSIBILIDADE DE } \\
\text { USURPAÇÃO DO PODER POLÍTICO. }\end{array}$ & $\begin{array}{l}\text { NÃO É UM AUMENTO DA LITIGÂNCIA } \\
\text { JURÍDICA EM SI, MAS UM PROCESSO DE } \\
\text { AUMENTO DA APLICABILIDADE DO } \\
\text { DIREITO; INTERFERÊNCIA JUDICIÁRIA É } \\
\text { UM FENÔMENO POSSIBILITADO PELOS } \\
\text { POLITICOS, DEVIDO A UMA INFLAÇÃO DO } \\
\text { ATO DE LEGISLAR E DA FALTA DE } \\
\text { CLAREZA DOS TEXTOS LEGAIS. }\end{array}$ \\
\hline $\begin{array}{r}\text { TATE \& } \\
\text { VALLINDER } \\
\text { (1995) }\end{array}$ & $\begin{array}{l}\text { CONSEQUÊNCIA DA QUEDA DO } \\
\text { COMUNISMO E DA UNIÃO SOVIÉTICA, } \\
\text { COM OS EUA COMO A ÚNICA } \\
\text { POTÊNCIA MUNDIAL, TORNANDO } \\
\text { A INSTITUIÇÃO DA REVISÄO JUDICIAL } \\
\text { NORTE-AMERICANA NUM MODELO } \\
\text { A SER SEGUIDO. }\end{array}$ & $\begin{array}{l}\text { A CRIATIVIDADE NÃO É INERENTE } \\
\text { À ATIVIDADE JURISDICIONAL, MAS } \\
\text { É POSSÍVEL E ACEITÁVEL. }\end{array}$ & $\begin{array}{l}\text { APRESENTA DOIS COMPONENTES: } \\
\text { UMA NOVA DISPOSIÇÃO DOS TRIBUNAIS } \\
\text { JUDICIAIS, EXPANDINDO O ESCOPO } \\
\text { DAS QUESTÕES SOBRE AS QUAIS DEVEM } \\
\text { FORMAR JUÍZOS JURISPRUDENCIAIS } \\
\text { E O INTERESSE DE POLÍTICOS E } \\
\text { AUTORIDADES ADMINISTRATIVAS EM } \\
\text { ADOTAR PROCEDIMENTOS SEMELHANTES } \\
\text { AOS JUDICIAIS. }\end{array}$ \\
\hline $\begin{array}{r}\text { WERNECK } \\
\text { VIANNA } \\
(1999,2002)\end{array}$ & $\begin{array}{l}\text { EXPANSÃO DO PRINCÍPIO } \\
\text { DEMOCRÁTICO IMPLICOU NUMA } \\
\text { CRESCENTE INSTITUCIONALIZAÇÃO } \\
\text { DO DIREITO NA VIDA SOCIAL. }\end{array}$ & $\begin{array}{l}\text { CONCORDA COM CAPPELLETTI } \\
\text { QUANTO À IMPORTÂNCIA DOS } \\
\text { JUÍZES NO PROCESSO DECISÓRIO. }\end{array}$ & $\begin{array}{l}\text { JUDICIALIZAÇÃO VISTA EM TERMOS } \\
\text { DE PROCEDIMENTALIZAÇÃOO DO DIREITO } \\
\text { E DA AMPLIAÇÃOO DOS INSTRUMENTOS } \\
\text { JUDICIAIS. }\end{array}$ \\
\hline $\begin{array}{r}\text { FARO DE } \\
\text { CASTRO } \\
\text { (1997) }\end{array}$ & - & $\begin{array}{l}\text { ENXERGA NO ATIVISMO UMA } \\
\text { POTENCIALIDADE PARA A } \\
\text { JUDICIALIZAÇÃO DA POLÍTICA. }\end{array}$ & $\begin{array}{l}\text { A MESMA DEFINIÇÃO ELABORADA } \\
\text { POR TATE E VALLINDER (1995). }\end{array}$ \\
\hline $\begin{array}{r}\text { ROGÉRIO } \\
\text { ARANTES } \\
(1999,2002)\end{array}$ & - & $\begin{array}{l}\text { NÃO DESCONSIDERA A } \\
\text { IMPORTÂNCIA, MAS ACEITA OUTROS } \\
\text { ELEMENTOS MAIS CENTRAIS PARA } \\
\text { A JUDICIALIZAÇÃO DA POLÍTICA. }\end{array}$ & $\begin{array}{l}\text { REQUER UMA DESCRIÇÃO DO QUADRO } \\
\text { INSTITUCIONAL E DAS REGRAS QUE } \\
\text { PERMITEM OU IMPEDEM AÇÕES } \\
\text { TIPICAMENTE POLÍTICAS POR PARTE } \\
\text { DOS TRIBUNAIS. }\end{array}$ \\
\hline
\end{tabular}

Fonte: Oliveira e Carvalho (2006). Com acréscimos dos autores.

Com relação aos fatores que impulsionariam a judicialização, também não há concordância. No presente trabalho, a intenção é analisar, na literatura especializada, se o Ministério Público teria algum poder explicativo na análise do processo de judicialização da política. Partindo do pressuposto de que o termo deve se aplicar não só aos juízes, mas também a outras carreiras judiciais, notadamente os membros do Ministério Público, estes últimos podem ser considerados responsáveis por tal fenômeno. Os promotores e procuradores usam suas competências para levar certos tipos de conflito à justiça ou para resolvê-los de forma extra-judicial. Segundo Arantes, "O Ministério Público tem sido o agente mais importante da defesa de direitos coletivos pela via judicial e, dado que os conflitos relativos a tais direitos têm 
geralmente conotação política, pode-se dizer que também tem impulsionado um processo mais amplo de judicialização de conflitos políticos” (1999: 83).

Já Casagrande (2008) considera a aquisição de autonomia pelo Ministério Público um dos vetores que impulsionaram o processo de politização da justiça no Brasil $^{11}$. Para ele, as garantias e prerrogativas adquiridas pelos promotores e procuradores na Constituição de 1988 vêm conferindo um novo papel no seu modo de atuar. Com efeito, a criação de um Ministério Público com um alto grau de autonomia e discricionariedade frente aos Poderes do Estado somada à ampliação de atribuições para a proteção do interesse público e dos direitos sociais seriam fatores explicativos para o processo de judicialização da política.

Entretanto, embora se admita que o Ministério Público "tem desempenhado o papel de coordenação e mediação entre as diversas agências estatais, valendo-se de maneira significativa de instrumentos extrajudiciais na resolução de disputas" (MACIEL; KOERNER, 2002: 126), isso por si só não seria suficiente para incentivar a judicialização (VIANNA, 2002).

Aparece aqui [no trabalho de Vianna (2002)] a figura do MP mais como um agente de mediação entre agentes sociais e poderes políticos do que um agente de judicialização, que provoca a intervenção de um poder externo e supostamente despolitizado a fim de solucionar de forma tutelar os conflitos (MACIEL; KOERNER, 2002: 12).

A tabela abaixo resume essas visões.

\section{Tabela 2 - Ministério Público e judicialização da política}

\begin{tabular}{|c|c|}
\hline AUTOR & ARGUMENTO \\
\hline $\begin{array}{r}\text { ARANTES } \\
(1999,2002)\end{array}$ & $\begin{array}{l}\text { O MINISTÉRIO PÚBLICO TEM SIDO O AGENTE MAIS IMPORTANTE DA DEFESA DE DIREITOS COLETIVOS PELA VIA } \\
\text { JUDICIAL E, DADO QUE OS CONFLITOS RELATIVOS A TAIS DIREITOS TÊM GERALMENTE CONOTAÇÃO POLÍTICA, } \\
\text { PODE-SE DIZER QUE TAMBÉM TEM IMPULSIONADO UM PROCESSO MAIS AMPLO DE JUDICIALIZAÇÃO DE } \\
\text { CONFLITOS POLITIICOS. }\end{array}$ \\
\hline $\begin{array}{r}\text { VIANNA } \\
\text { (2002) }\end{array}$ & $\begin{array}{l}\text { O MINISTÉRIO PÚBLICO TEM DESEMPENHADO UM PAPEL DE COORDENAÇÃO E MEDIACCÃO ENTRE AS DIVERSAS } \\
\text { AGÊNCIAS ESTATAIS, VALENDO-SE DE MANEIRA SIGNIFICATIVA DE INSTRUMENTOS EXTRAJUDICIAIS NA RESOLUÇĀO } \\
\text { DE DISPUTAS, MAS ISSO POR SI SÓ NĀO SERIA SUFICIENTE PARA INCENTIVAR A JUDICIALIZAÇĀO. A FIGURA } \\
\text { DO MP APARECE MAIS COMO UM AGENTE DE MEDIAÇĀO ENTRE AGENTES SOCIAIS E PODERES POLÍTICOS DO } \\
\text { QUE UM AGENTE DE JUDICIALIZAC̣ĀO. }\end{array}$ \\
\hline $\begin{array}{r}\text { CASAGRANDE } \\
\text { (2008) }\end{array}$ & 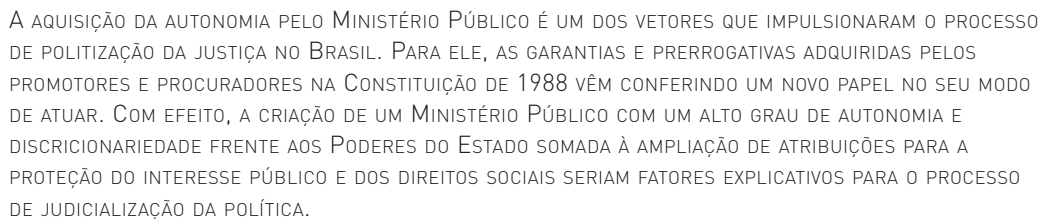 \\
\hline
\end{tabular}

Fonte: elaboração própria 
De fato, o novo desenho institucional do Ministério Público e as prerrogativas adquiridas pelos seus membros não devem ser considerados fatores suficientes para a explicação do processo de judicialização. Mas, sem dúvida, a instituição tem um papel central no estudo do fenômeno no Brasil.

\section{CONCLUSÃo}

Este trabalho buscou debater alguns aspectos relevantes do novo desenho institucional do Ministério Público e sua relação com o fenômeno de judicialização da política. Certamente, as garantias e prerrogativas asseguradas pela Constituição de 1988 fizeram com essa instituição adquirisse um alto grau de autonomia e discricionariedade, tendo essas características alguma relevância no processo de judicialização.

Embora se admita que a questão de avaliação do grau de autonomia real do Ministério Público é eminentemente empírica (SADEK, 2000), o presente trabalho abordou alguns critérios importantes de avaliação apontados pela literatura e os motivos pelos quais o Ministério Público conseguiu essa autonomia. Retomando alguns pontos centrais, esse perfil institucional é bastante peculiar, principalmente se comparado ao perfil de outras agências estatais brasileiras. Sendo assim, alguns trabalhos na Ciência Política nacional surgiram no intuito de explicar esse novo modelo. Embora ainda incipiente e com algumas limitações, o debate traz variáveis importantes que devem ser consideradas e servem como um norte para novas pesquisas.

Além disso, acredita-se que o grau de autonomia e discricionariedade adquirido pelo Ministério Público deveria ser acompanhado por mecanismos eficientes de controle e accountability. Como analisado, isso não aconteceu. Os mecanismos são frágeis e deixam ampla margem para a atuação autônoma dos membros do Parquet. Embora a situação pareça um tanto insolúvel, alguns mecanismos têm potencialidade se ser eficientes, se "corrigidas" suas falhas. O controle orçamentário, por exemplo, pode ser um mecanismo adequado. Mesmo que não atinja diretamente os integrantes da instituição, pode interferir na sua efetividade, o que já é um importante passo.

Com relação ao impacto que esse novo desenho institucional tem sobre o atual e tão estudado fenômeno de judicialização da política, como vimos, há discordâncias tanto no que se refere à força desse impacto quanto à sua forma. Todavia, o Ministério Público pode ser considerado um eficiente catalisador do processo de judicialização da política.

Por fim, destacamos que ainda há um leque de problemas que a agenda de pesquisa sobre o Ministério Público pode resolver. A instituição aparece cada vez mais como um importante ator político do processo de tomada de decisões e sua influência cresce como um dos órgãos do Sistema de Justiça. Algumas pesquisas 
importantes surgiram com o objetivo de suprir a necessidade de estudos sobre essa crescente influência (SADEK, 1997; SADEK, 2000; ARANTES, 2000; SILVA, 2001; BRASIL, 2006). Contudo, muito mais do que fornecer respostas, o objetivo do presente trabalho foi suscitar questões que, sem dúvida, são importantes para pesquisas futuras.

: ARTIGo APRoVAdo (03/11/2010) : RECEBIDO EM 01/07/2010

\section{NOTAS}

1 O mais comum é indicar a origem do Ministério Público nos procuradores do rei da França. Como uma alusão às origens históricas francesas, o termo Parquet (assoalho das salas de audiência, sobre o qual esses magistrados tinham assento) é utilizado frequentemente para se referir ao Ministério Público (MAZZILLI, 2005).

2 Recentemente, o Ministério Público tem se utilizado bastante dos Termos de Ajustamento de Conduta, que é uma espécie de acordo que o Ministério Público propõe, como uma forma de evitar o ajuizamento da ação civil pública, ou seja, uma forma da instituição resolver questões sem acionar o Judiciário.

${ }^{3}$ As atividades-fim são aqueles atos para os quais a Constituição destinou a instituição ministerial, como a defesa dos interesses sociais. Elas de diferenciam das atividades-meio, que são os atos administrativos que a instituição pratica, como a nomeação ou promoção de promotores e procuradores (MAZZILLI, 2005: 38).

${ }^{4}$ Em uma obra seminal, Olson (1999) vai de encontro à ideia de que "grupos de indivíduos com interesses comuns usualmente tentam promover esses interesses comuns” (OLSON, 1999:13). Ou seja, ele tenta mostrar que a noção de que quando os indivíduos fazem parte de um grupo eles agem voluntariamente com o objetivo de alcançar seus interesses comuns, tanto quanto eles fazem para atingir seus interesses pessoais, não é verdadeira, como defendida por muitos estudiosos. Para ele, os indivíduos racionais e centrados nos seus próprios interesses não atuarão no sentido de promover seus interesses comuns, mesmo que saiam ganhando se agirem como grupo para atingir tais interesses.

5 O “centrão” foi um bloco suprapartidário e de caráter conservador formado a partir de insatisfações com os rumos da Constituinte. Esse grupo fez uma campanha pela reforma do Regimento Interno, o que acabou sendo conseguido.

6 Neste modelo, o principal representa aquele que delega e o agent aquele a quem a autoridade é delegada (LUPIA, 2001).

7 A definição de accountability tem duas dimensões básicas: a responsividade que se refere à compatibilidade entre a ação de um agent e a preferência de seu principal e a responsabilização que diz respeito à obrigatoriedade do respeito a esta compatibilidade.

8 Abdicação aqui é entendida no sentido de que os políticos não têm nenhum mecanismo para controlar o Ministério Público. Como já foi mostrado, apesar de insuficientes, os mecanismos existem.

${ }^{9}$ A accountability se dá em dois níveis, no vertical, exercida através dos cidadãos pelo voto e no horizontal, exercida entre as agências do Estado (O’DONNELL, 1998). 
10 A judicialização da política tem como fenômeno correlato a politização da justiça, ambos indicando, grosso modo, os efeitos da expansão do Poder Judiciário no processo decisório das democracias contemporâneas (TATE; VALLINDER, 1995).

11 Casagrande (2008) atribui a politização da justiça aos seguintes fatores: a) a criação de um modelo constitucional amplamente regulatório dos direitos individuais e sociais, com a prevalência do direito público sobre o direito privado, consagrado na ideia de "Constituição Cidadã"; b) a ampliação do sistema de controle de constitucionalidade; c) a independência do Poder Judiciário e do Ministério Público; e d) ampliação do acesso à Justiça, por meio de novas formas processuais (ações coletivas, ações diretas para controle de constitucionalidade, etc.) e da abertura de novos canais do sistema de justiça (Ministério Público, Defensoria Pública, juizados especiais, órgãos de defesa do consumidor e da concorrência, Comissões Parlamentares de Inquérito).

\section{REFERÊNCIAS BIBLIOGRÁFICAS}

ARANTES, Rogério Bastos. Direito e política: o Ministério Público e a defesa dos direitos coletivos. Revista Brasileira de Ciências Sociais, 14, 39: 83-102, 1999.

. Ministério Público e Corrupção Política em São Paulo. In: SADEK, Maria Tereza (org.). Justiça e

cidadania no Brasil. São Paulo: Sumaré, 2000.

. Ministério público e política no Brasil. São Paulo: Educ/Sumaré, 2002.

BENDOR, Jonathan et al. Theories of delegation. Annual review of political science, 4: 235-269, 2001.

BONAVIDES, Paulo; ANDRADE, Paes de. A Constituinte e a Constituição de 1988. In: BONAVIDES, Paulo; ANDRADE, Paes de. História Constitucional do Brasil. Brasília: Paz e Terra/Senado Federal, 1989.

CAPPELLETTI, Mauro. Juízes Legisladores?. Porto Alegre: Sérgio Antônio Fabris Editor, 1993.

CARVALHO, Ernani. "Em busca da judicialização da política no Brasil: apontamentos para uma nova abordagem”. Revista. Sociologia e Política. 23: 127-139, 2004.

CASAGRAnDE, Cássio. Ministério Público e Judicialização da Política - cinco estudos de caso. Porto Alegre, Sérgio Antônio Fabris Editor, 2008.

CASTRO, Marcos Faro de. "O Supremo Tribunal Federal e a Judicialização da Política". Revista Brasileira de Ciências Sociais. 12, 34, 1997.

CAVALCANTI, Rosângela Batista. "Ministério Público na Paraíba”. In: SADEK, Maria Tereza (org.). Justiça e

cidadania no Brasil. São Paulo: Sumaré, 2000.

GARAPON, Antoine. O juiz e a democracia: o guardião de promessas. Rio de Janeiro, Revan, 1999.

HALL, Peter A.; TAYLOR, Rosemary C. R. "As três versões do neo-institucionalismo". Lua Nova, 58 : 193

223, 2003.

KERCHE, Fábio. “O Ministério Público e a Constituinte de 1987/88”. In: SADEK, Maria Tereza (org.). O sistema de Justiça. São Paulo: IDESP/Sumaré, 1999.

O Ministério Público no Brasil: autonomia, organização e atribuições. Tese de Doutorado, Dept. Ciência Política, USP, 2003.

KINZO, Maria D’Alva Gil.. “O quadro partidário e a constituinte”. In: LAMOUNIER, Bolívar (org.), De Geisel a Collor: o balanço da transição. São Paulo: IDESP/Sumaré, 1990.

LUPIA, Arthur. Delegation of power: agency theory. In: Neil Smelser e Paul Baltes (orgs.), International encyclopedia of the social behavioral sciences. Oxford: Elsevier science limited, 2001.

MACIEL, Débora; KOERNER, Andrei. Sentidos da judicialização da política: duas análises. Lua Nova, 57: $113-$

$133,2002$.

MAZZILLI, Hugo Nigro. Ministério Público. 3. ed. São Paulo: Damásio de Jesus, 2005.

MELO, Marcus André. “Governance e reforma do estado: o paradigma agente x principal”. Revista do Servidor Público, 120, 1: 67-79, 1996.

MILLER, Gary J. The political evolution of principal-agent models. Annual review of political science, 8: $203-$ $225,2005$.

O’DONNELL, Guillermo. Democracia delegativa?. Novos Estudos, 31: 25-40, 1991. . Accountability horizontal e novas poliarquias. Lua Nova, 44: 27-53, 1998.

Terra, 2000

et al. (orgs.). Democracia, violência e injustiça: o não-Estado de direito na América Latina. São Paulo: Paz e 
OLIVEIRA, Vanessa; CARVALHO, Ernani. A judicialização da política: um tema em aberto. Revista Política Hoje, 1, 15, 2006.

OLSON, Mancur. A lógica da ação coletiva: os benefícios públicos e uma teoria dos grupos sociais. São Paulo: Editora da Universidade de São Paulo, 1999.

PRZEWORSKI, Adam. Sobre o Desenho Institucional do Estado: Uma Perspectiva Agent x Principal. In: PEREIRA, Bresser (org.). Reforma do Estado e administração pública gerencial. Rio de Janeiro: Fundação Getúlio Vargas, 1998. SADEK, Maria Tereza (org). O Ministério Público e a Justiça no Brasil. São Paulo: Sumaré, Idesp, 1997. . O sistema de justiça. In: SADEK, Maria Tereza (org.). O sistema de justiça. São Paulo: IDESP/Sumaré, 1999. . Cidadania e Ministério Público. In: SADEK, Maria Tereza (org). Justiça e cidadania no Brasil. São Paulo: Sumaré, 2000.

SALAZAR, Juliana. O desenho institucional do Ministério Público: o Procurador-Geral da República e as Ações Diretas de Inconstitucionalidade. Dissertação de Mestrado, Programa de Pós-Graduação em Ciência Política, UFPE, 2007. SILVA, Catia Aida. Justiça em jogo: novas facetas da atuação dos promotores de justiça. São Paulo: Edusp, 2001. TATE, Neal; VALLINDER, Torbjorn. The global expansion of judicial power: the judicialization of politics. New York, New York University Press, 1995.

VIANNA, Luiz Werneck et al. A judicialização da política e das relações sociais no Brasil. Rio de Janeiro, Revan, 1999. VIANNA, Luiz Werneck (org). A democracia e os Três Poderes no Brasil. Belo Horizonte: Editora UFMG; Rio de Janeiro: IUPERJ/FAPERJ, 2002.

\section{DOCUMENTOS OFICIAIS}

BRASIL. Lei complementar no 75, de 20 de maio de 1993.

BRASIL. Constituição da República Federativa do Brasil, de 05 de outubro de 1988.

CONAMP. Carta de Curitiba, de 21 de junho de 1986.

BRASIL, Ministério da Justiça. Diagnóstico Ministério Público nos Estados, 2006.

\section{SITES CONSULTADOS}

Associação Nacional dos Membros do Ministério Público - www.conamp.org.br Conselho Nacional do Ministério Público - http://www.cnmp.gov.br/ Ministério Público da União - http://www.mpu.gov.br

\section{Ernani Carvalho}

Rua Acadêmico Hélio Ramos - s/n - 14º andar Cidade Universitária - 50670-901

Recife - PE - Brasil

ernani.carvalholapq.cnpq.br

Cidade Universitária - 50670-901 Recife - PE - Brasil

natalialeitaolgmail.com
Doutor EM CIÊNCIA POLítica PELA Universidade de SÃo PAUlo

(USP)

ProfESSOR DO DEPARTAMENTO DE CIÊNCIA POLÍTICA DA Universidade Federal de Pernambuco (UFPE)

PESQUisAdOR DO CNPQ - NÍvel 2

Natália Leitão

Mestranda em CIÊNCIA POLÍTICA PELA Universidade FEDERAL de Pernambuco (UFPE) 